\title{
The use of SGLT2 inhibitors in achieving glycaemic control in maturity-onset diabetes of the young type 3
}

\author{
Arunan Sriravindrarajah $\mathbb{D}^{1,2}$, Amelia Fernandes ${ }^{1,3}$, Ted Wu $\mathbf{u}^{1,2}$ and Samantha Hocking $1,2,4$ \\ ${ }^{1}$ Royal Prince Alfred Hospital, Sydney, Australia, 2Faculty of Medicine and Health, University of Sydney, Sydney, \\ Australia, ${ }^{3}$ Faculty of Medicine, University of New South Wales, Sydney, Australia, and ${ }^{4}$ Charles Perkins Centre, \\ University of Sydney, Sydney, Australia
}

Correspondence

should be addressed

to A Sriravindrarajah

Email

asri6074@uni.sydney.edu.au

\section{Summary}

Maturity-onset diabetes of the young type 3 (MODY3) accounts for approximately 50\% of cases of MODY. First-line treatment with sulfonylureas has been well established for individuals with MODY3. In contrast, the use of sodium-glucose co-transporter 2 (SGLT2) inhibitors in the treatment of individuals with MODY3 remains unclear. This case illustrates the in vivo effect of an SGLT2 inhibitor in a 30-year-old woman with MODY3 with poor glycaemic control despite the treatment with supramaximal doses of sulfonylurea and metformin. The addition of a SGLT2 inhibitor resulted in a rapid improvement in glycaemic control without any hypoglycaemic episodes. This case suggests that SGLT2 inhibitors may be an effective and potent treatment option in addition to sulfonylureas for individuals with MODY3.

\section{Learning points:}

- Maturity-onset diabetes of the young type 3 (MODY3) arises from mutations in the hepatocyte nuclear factor1 alpha gene, which controls the expression of sodium-glucose co-transporter 2 (SGLT2) in the kidneys.

- Paradoxically, despite individuals with MODY3 having reduced expression of SGLT2, SGLT2 inhibitors induce higher glycosuria in individuals with MODY3 compared to individuals with type 2 diabetes mellitus.

- SGLT2 inhibitors may be an effective treatment for achieving glycaemic control in individuals with MODY3.

\section{Background}

Maturity-onset diabetes of the young (MODY) is the most common type of monogenic diabetes mellitus and is estimated to account for $1-5 \%$ of all diabetes mellitus cases $(1,2)$. It is characterised by diagnosis at a young age (typically under 35 years), the absence of islet autoantibodies and autosomal dominant inheritance of a single gene mutation $(1,3)$. MODY3 accounts for approximately $50 \%$ of cases of MODY and arises from mutations in the hepatocyte nuclear factor-1alpha $(H N F-1 A)$ gene $(3,4,5,6)$. Patients with MODY3 develop a progressive deterioration in insulin secretion leading to increasing hyperglycaemia $(1,3,7,8)$. Extra-pancreatic features of MODY3 include a lower renal threshold for glycosuria, which occurs due to reduced expression of the sodium-glucose co-transporter 2 (SGLT2) that is under direct transcriptional control by $H N F-1 A(8,9,10)$. Individuals with MODY3 ultimately require treatment as they develop microvascular and macrovascular complications of diabetes mellitus at a similar frequency to patients with type 1 (T1D) and type 2 diabetes mellitus (T2D) with the rate of complications proportional to the degree of hyperglycaemia $(3,11)$. A feature of the $\beta$-cell defect in MODY3 is an increased sensitivity to the hypoglycaemic effects of sulfonylureas compared with patients with T2D $(12,13,14)$. Given the 
progressive nature of MODY3, individuals will ultimately develop worsening glycaemic control despite maximal doses of sulfonylureas, and further treatment is required to prevent diabetic complications. Treatment with insulin is typically required in advanced MODY3 disease, although glucagon-like peptide- 1 receptor agonists and dipeptidyl peptidase- 4 inhibitors have also been shown to be effective $(1,3,15,16,17,18)$.

We report the case of a 30-year-old woman with MODY3 with persistent hyperglycemia on supramaximal doses of sulfonylurea and metformin, who experienced a marked improvement in glycaemic control upon initiation of treatment with an SGLT2 inhibitor.

\section{Case presentation}

A 30-year-old Caucasian female was admitted with osteomyelitis and septic arthritis of the right 1st metatarsal bone and metatarsophalangeal joint. This was in the setting of a chronic diabetic foot ulcer present for 15 months, despite treatment with a continuous infusion of intravenous flucloxacillin $8 \mathrm{~g}$ daily for the preceding 5 weeks.

She had a background of MODY3 which was initially misdiagnosed at age 18 as T1D. She was initially commenced on insulin for 6 months, but when diagnosed with MODY3, gliclazide modified release (MR) $60 \mathrm{mg}$ daily and metformin extended release (XR) $500 \mathrm{mg}$ daily were commenced. Her glycaemic control was excellent at age 19 with glycosylated haemoglobin (HbA1c) $48 \mathrm{mmol} /$ mol, but deteriorated over time such that her HbA1C was $112 \mathrm{mmol} / \mathrm{mol}$ by 2019 when she developed her diabetic foot ulcer. Her glycaemic control remained poor despite the intensification of her oral hypoglycaemic therapy to supramaximal doses of gliclazide MR $120 \mathrm{mg}$ twice daily and metformin XR $2 \mathrm{~g}$ BD.

\section{Investigation}

At the time of admission, she was haemodynamically stable and afebrile. Her C-reactive protein (CRP) was $27.3 \mathrm{mg} / \mathrm{L}$, and an $\mathrm{x}$-ray showed erosion of the 1st metatarsal head and proximal phalanx consistent with osteomyelitis and likely septic arthritis. Her HbA1C was $67 \mathrm{mmol} / \mathrm{mol}$, and she had persistent hyperglycaemia with capillary blood glucose levels (BGLs) ranging from 5.9 to $18.0 \mathrm{mmol} / \mathrm{L}$.

\section{Treatment}

The patient was commenced on empagliflozin $10 \mathrm{mg}$ daily in addition to her regular gliclazide MR $120 \mathrm{mg}$ BD and metformin XR $2 \mathrm{~g}$ twice daily. Her glycaemic control immediately improved with her BGL ranging from 4.2 to $7.5 \mathrm{mmol} / \mathrm{L}$ (Fig. 1). The weighted average BGL was reduced from 8.53 to $5.65 \mathrm{mmol} / \mathrm{L}$ after the initiation of empagliflozin. She was also treated with intravenous flucloxacillin $2 \mathrm{~g}$ four times a day and twice-weekly wound dressings for her foot ulcer.

\section{Outcome and follow-up}

Following the rapid improvement in glycaemic control with the introduction of empagliflozin, the doses of the patient's other oral hypoglycaemic medications were
Daily Blood Glucose Profile

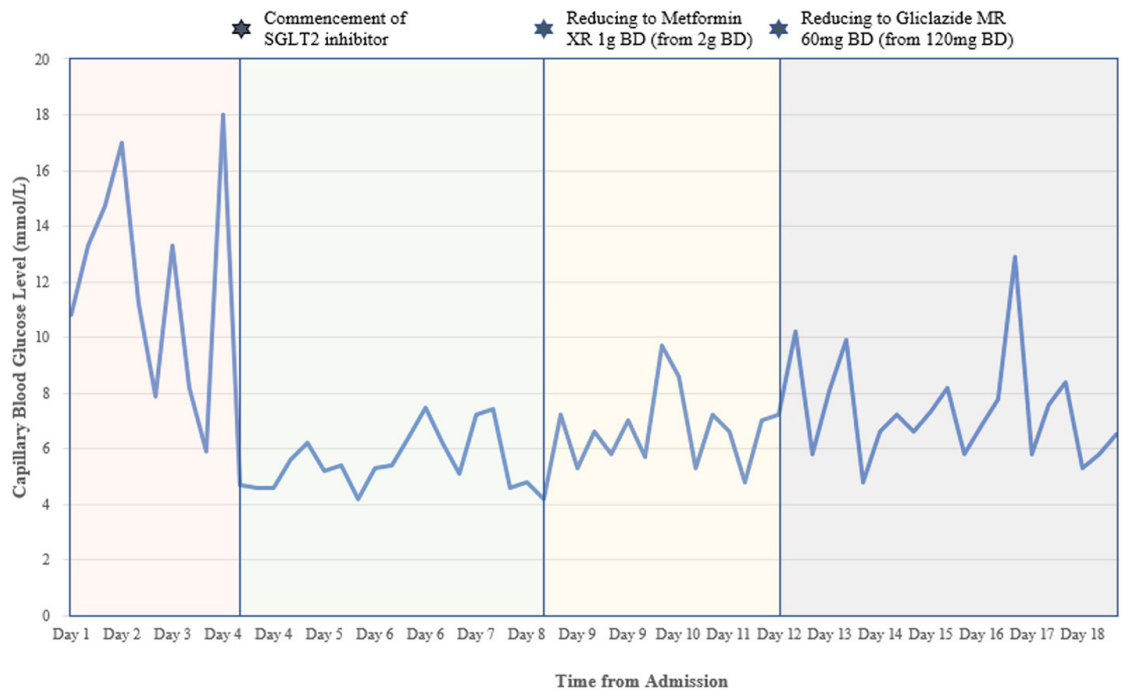

Figure 1

Daily blood glucose profile. 
reduced to the maximum recommended daily dose of metformin XR $1 \mathrm{~g}$ BD and gliclazide MR $60 \mathrm{mg}$ twice daily. This resulted in an increase in the weighted average BGL levels to $6.89 \mathrm{mmol} / \mathrm{L}$.

Her foot ulcer also improved with a reduction in pain, erythema and slough. Her CRP declined to $1.1 \mathrm{mg} / \mathrm{L}$, and she was discharged on oral flucloxacillin $1 \mathrm{~g}$ four times a day for a further 4 weeks and ongoing twice-weekly dressing changes. Her ulcer has continued to heal, the osteomyelitis has resolved and she has now commenced mobilising with an off-loading boot.

\section{Discussion}

This case demonstrates the efficacy of SGLT2 inhibitors in the treatment of MODY3. The addition of a SGLT2 inhibitor to a pre-existing regimen of supramaximal doses of gliclazide and metformin immediately achieved excellent glycaemic control in a poorly controlled MODY3 patient. Furthermore, there were no episodes of hypoglycaemia despite the addition of an extra oral hypoglycaemic agent.

SGLT2 inhibitors are a newer class of medications for the treatment of T2D (19). These agents block the low-affinity, high-capacity glucose transporter located in the proximal tubule in the kidneys, and thus induce glycosuria to lower serum blood glucose levels (BGL) (20). It would be predicted from a pathophysiological basis that SGLT2 inhibitors would have reduced efficacy in MODY3 individuals compared to individuals with T2D due to their inherent reduction in SGLT2 expression secondary to their defect in HNF-1A (9). Yet a small study demonstrated that SGLT2 inhibitors paradoxically induced higher glycosuria in individuals with MODY3 compared to individuals with T2D, suggesting this novel antihyperglycaemic class may be an effective therapeutic option for patients with MODY3 (21). The mechanism by which SGLT2 inhibitors increase glycosuria in MODY3 remains unknown.

In humans, SGLT2 is responsible for reabsorption of $\sim 97 \%$ of the filtered glucose; however, SGLT2 inhibitors block the reabsorption of only $\sim 50-60 \%$ of renally filtered glucose $(22,23)$. It has been proposed that SGLT1mediated glucose reabsorption increases in the presence of SGLT2 inhibition, accounting for the discrepancy between observed and anticipated glycosuria $(22,23)$. Indeed, SGLT1 knockout mice have significantly greater levels of SGLT2 inhibitor mediated glycosuria, supporting the hypothesis that changes in SGLT1 expression could explain the increased effectiveness of SGLT2 inhibitors. Yet, previous studies have shown HNF-1A mutant animals express SGLT1 at the same levels and efficiency as control animals, and thus a reduction in the expression or function of SGLT1 is unlikely to be the mechanism via which SGLT2 inhibitors promote more glycosuria in MODY3 patients (9).

The pleiotropic impact of SGLT2 inhibitors may be involved in the effectiveness of SGLT2 inhibitors in patients with MODY3. SGLT2 inhibitors have been shown to have an array of effects such as increasing insulin sensitivity, improving $\beta$-cell function and shifting substrate utilisation from carbohydrates to lipids (24). These factors may explain some of the underlying mechanisms of the effectiveness of SGLT2 inhibitors in MODY3 patients.

A potential limitation of this case is distinguishing the impact on glycaemic control of the addition of a SGLT2 inhibitor versus the ongoing treatment of the underlying osteomyelitis. However, the degree of glycaemic improvement demonstrated was above that expected from the treatment of osteomyelitis alone and likely reflects a true reduction in BGLs from the commencement of the SGLT2 inhibitor. Further research is required to better elucidate the precise mechanism whereby SGLT2 inhibitors induce increased glycosuria in MODY3 patients compared to those with T2D. The use of SGLT2 inhibitors in MODY3 patients also requires caution given the characteristic impairment of insulin secretion in MODY3 may predispose these patients to a higher risk of euglycaemic diabetic ketoacidosis $(1,3,8$, $25)$. The lower threshold for glycosuria in MODY3 patients may also lead to higher levels of polyuria exceeding that observed in T2D patients, with a possible increased risk of volume depletion and dehydration $(8,9,10)$. Nonetheless, this case demonstrates the effectiveness of an SGLT2 inhibitor in addition to a sulfonylurea and metformin in achieving glycaemic control in a patient with MODY3. SGLT2 inhibitors should be considered as part of the armamentarium available for clinicians treating patients with MODY3.

\section{Declaration of interest}

The authors declare that there is no conflict of interest that could be perceived as prejudicing the impartiality of the research reported.

\section{Funding}

This study did not receive any specific grant from any funding agency in the public, commercial or not-for-profit sector.

\section{Patient consent}

Written informed consent was obtained from the patient for publication of this case report. 


\section{Author contribution statement}

Arunan Sriravindrarajah, Amelia Fernandes, Ted Wu and Samantha Hocking have been involved in the patient care and drafted the case report.

\section{References}

1 Nkonge KM, Nkonge DK \& Nkonge TN. The epidemiology, molecular pathogenesis, diagnosis, and treatment of maturity-onset diabetes of the young (MODY). Clinical Diabetes and Endocrinology 2020620. (https://doi.org/10.1186/s40842-020-00112-5)

2 Urakami T. Maturity-onset diabetes of the young (MODY): current perspectives on diagnosis and treatment. Diabetes, Metabolic Syndrome and Obesity: Targets and Therapy 201912 1047-1056. (https://doi. org/10.2147/DMSO.S179793)

3 Delvecchio M, Pastore C \& Giordano P. Treatment options for MODY patients: a systematic review of literature. Diabetes Therapy 202011 1667-1685. (https://doi.org/10.1007/s13300-020-00864-4)

4 Shields BM, Hicks S, Shepherd MH, Colclough K, Hattersley AT \& Ellard S. Maturity-onset diabetes of the young (MODY): how many cases are we missing? Diabetologia 201053 2504-2508. (https://doi. org/10.1007/s00125-010-1799-4)

5 Hoffman LS, Fox TJ, Anastasopoulou C \& Jialal I. Maturity Onset Diabetes in the Young. Treasure Island (FL): StatPearls Publishing, 2020. (https://www.ncbi.nlm.nih.gov/books/NBK532900)

6 Yamagata K, Oda N, Kaisaki PJ, Menzel S, Furuta H, Vaxillaire M, Southam L, Cox RD, Lathrop GM, Boriraj VV, et al. Mutations in the hepatocyte nuclear factor-1 $\alpha$ gene in maturity-onset diabetes of the young (MODY3). Nature 1996384 455-458. (https://doi. org $/ 10.1038 / 384455 \mathrm{a} 0)$

7 Fajans SS \& Brown MB. Administration of sulfonylureas can increase glucose-induced insulin secretion for decades in patients with maturity-onset diabetes of the young. Diabetes Care 199316 1254-1261. (https://doi.org/10.2337/diacare.16.9.1254)

8 Stride A, Ellard S, Clark P, Shakespeare L, Salzmann M, Shepherd M $\&$ Hattersley AT. $\beta$-Cell dysfunction, insulin sensitivity, and glycosuria precede diabetes in hepatocyte nuclear factor- $1 \alpha$ mutation carriers. Diabetes Care 200528 1751-1756. (https://doi.org/10.2337/ diacare.28.7.1751)

9 Pontoglio M, Prié D, Cheret C, Doyen A, Leroy C, Froguel P, Velho G, Yaniv M \& Friedlander G. HNF1 $\alpha$ controls renal glucose reabsorption in mouse and man. EMBO Reports 20001 359-365. (https://doi. org/10.1093/embo-reports/kvd071)

10 Menzel R, Kaisaki PJ, Rjasanowski I, Heinke P, Kerner W \& Menzel S. A low renal threshold for glucose in diabetic patients with a mutation in the hepatocyte nuclear factor- $1 \alpha(\mathrm{HNF}-1 \alpha)$ gene. Diabetic Medicine 199815 816-820. (https://doi.org/10.1002/(SICI)10969136(199810)15:10<816::AID-DIA714>3.0.CO;2-P)

11 Isomaa B, Henricsson M, Lehto M, Forsblom C, Karanko S, Sarelin L, Häggblom M \& Groop L. Chronic diabetic complications in patients with MODY3 diabetes. Diabetologia 199841 467-473. (https://doi. org/10.1007/s001250050931)

12 Bacon S, Kyithar MP, Rizvi SR, Donnelly E, McCarthy A, Burke M, Colclough K, Ellard S \& Byrne MM. Successful maintenance on sulphonylurea therapy and low diabetes complication rates in a HNF1A-MODY cohort. Diabetic Medicine 201633 976-984. (https:// doi.org/10.1111/dme.12992)
13 Hattersley AT, Greeley SAW, Polak M, Rubio-Cabezas O, Njølstad PR, Mlynarski W, Castano L, Carlsson A, Raile K, Chi DV, et al. ISPAD Clinical Practice Consensus Guidelines 2018: the diagnosis and management of monogenic diabetes in children and adolescents. Pediatric Diabetes 201819 (Supplement 27) 47-63. (https://doi. org/10.1111/pedi.12772)

14 Pearson ER, Starkey BJ, Powell RJ, Gribble FM, Clark PM \& Hattersley AT. Genetic cause of hyperglycaemia and response to treatment in diabetes. Lancet 2003362 1275-1281. (https://doi. org/10.1016/S0140-6736(03)14571-0)

15 Naylor R, Knight Johnson A \& del Gaudio D. Maturity-Onset Diabetes of the Young Overview. Seattle (WA): University of Washington, 2018. (https://www.ncbi.nlm.nih.gov/books/NBK500456)

16 Østoft SH, Bagger JI, Hansen T, Pedersen O, Faber J, Holst JJ, Knop FK $\&$ Vilsbøll T. Glucose-lowering effects and low risk of hypoglycemia in patients with maturity-onset diabetes of the young when treated with a GLP-1 receptor agonist: a double-blind, randomized, crossover trial. Diabetes Care 201437 1797-1805. (https://doi.org/10.2337/ dc13-3007)

17 Broome DT, Tekin Z, Pantalone KM \& Mehta AE. Novel use of GLP-1 receptor agonist therapy in HNF4A-MODY. Diabetes Care 202043 e65. (https://doi.org/10.2337/dc20-0012)

18 Christensen AS, Hædersdal S, Støy J, Storgaard H, Kampmann U, Forman JL, Seghieri M, Holst JJ, Hansen T, Knop FK, et al. Efficacy and safety of glimepiride with or without linagliptin treatment in patients with HNF1A diabetes (maturity-onset diabetes of the young type 3): a randomized, double-blinded, placebo-controlled, crossover trial (GLIMLINA). Diabetes Care 202043 2025-2033. (https://doi. org/10.2337/dc20-0408)

19 Scheen AJ. Sodium-glucose cotransporter type 2 inhibitors for the treatment of type 2 diabetes mellitus. Nature Reviews: Endocrinology 202016 556-577. (https://doi.org/10.1038/s41574-020-0392-2)

20 Hsia DS, Grove O \& Cefalu WT. An update on sodium-glucose co-transporter- 2 inhibitors for the treatment of diabetes mellitus. Current Opinion in Endocrinology, Diabetes, and Obesity 201724 73-79. (https://doi.org/10.1097/MED.0000000000000311)

21 Hohendorff J, Szopa M, Skupien J, Kapusta M, Zapala B, Platek T, Mrozinska S, Parpan T, Glodzik W, Ludwig-Galezowska A, et al. A single dose of dapagliflozin, an SGLT-2 inhibitor, induces higher glycosuria in GCK- and HNF1A-MODY than in type 2 diabetes mellitus. Endocrine 201757 272-279. (https://doi.org/10.1007/ s12020-017-1341-2)

22 Brown E, Wilding JPH, Alam U, Barber TM, Karalliedde J \& Cuthbertson DJ. The expanding role of SGLT2 inhibitors beyond glucose-lowering to cardiorenal protection. Annals of Medicine 2020 1-32. (https://doi.org/10.1080/07853890.2020.1841281)

23 Novikov A \& Vallon V. Sodium glucose cotransporter 2 inhibition in the diabetic kidney: an update. Current Opinion in Nephrology and Hypertension 201625 50-58. (https://doi.org/10.1097/ MNH.0000000000000187)

24 Ferrannini E, Muscelli E, Frascerra S, Baldi S, Mari A, Heise T, Broedl UC \& Woerle HJ. Metabolic response to sodium-glucose cotransporter 2 inhibition in type 2 diabetic patients. Journal of Clinical Investigation 2014124 499-508. (https://doi.org/10.1172/JCI72227)

25 Ogawa W \& Sakaguchi K. Euglycemic diabetic ketoacidosis induced by SGLT2 inhibitors: possible mechanism and contributing factors. Journal of Diabetes Investigation 20167 135-138. (https://doi. $\operatorname{org} / 10.1111 /$ jdi.12401) 